\title{
Spinal intradural arteriovenous fistula mimicking intramedullary tumor and associated with a giant intracranial aneurysm
}

\author{
Wuilker Knoner Campos ${ }^{1}$, Benjamin Franklin da Silva², Jose Antônio Damian Guasti ${ }^{3}$
}

\begin{abstract}
Spinal intradural arteriovenous fistulas (AVFs) are a rare type of neurovascular malformation. Many a time hemodynamic disturbs associated to these entities can cause edema with subsequent myelopathy. On MRI study, this edema can mimic an intramedullary tumor. We report a rare case of spinal intradural AVFs mimicking an intramedullary tumor, which also were surprisingly associated with a giant intracranial aneurysm. We highlight in detail the MRI findings in intramedullary lesions, and also emphasize that these entities requires as careful differential diagnosis as supplementary investigation of the neuroaxis looking for other simultaneous neurovascular pathologies.

\section{KEY-WORDS}

Arteriovenous fistula, vascular malformations, spine, intracranial aneurysm, spinal cord/pathology.

\section{RESUMO}

Fistula arteriovenosa intradural espinhal mimetizando tumor intramedular e associado com aneurisma intracraniano gigante

Fístulas arteriovenosas espinhais intradurais são um tipo raro de malformação neurovascular. Muitas vezes, distúrbios hemodinâmicos associados a essa entidade podem causar edema com subsequente mielopatia. Em estudos de ressonância magnética, esse edema pode mimetizar um tumor intramedular. Relata-se um caso raro de fistula arteriovenosa espinhal intradural mimetizando um tumor intramedular, que também estava associado a um aneurisma cerebral gigante. Destacam-se em detalhes os achados de RM nas lesões intramedulares, assim como se enfatiza que essas entidades requerem tanto um diagnóstico diferencial criterioso quanto uma investigação complementar do neuroeixo procurando por outras patologias neurovasculares associadas.
\end{abstract}

\section{PALAVRAS-CHAVE}

Fístula arteriovenosa, malformações vasculares, coluna vertebral, aneurisma intracraniano, medula espinhal/patologia.

\section{Introduction}

Intradural spinal arteriovenous fistulas (AVFs), a subtype of spinal vascular malformation, are a direct communication between a spinal artery and a vein on the spinal cord surface or in the subarachnoid space. Spinal vascular malformations are a heterogeneous group of rare and still underdiagnosed pathological entities that classically may lead to progressive myelopathy if not early diagnosed and treated. ${ }^{4,8}$ Magnetic resonance imaging (MRI) is considered the first-line diagnostic modality of choice in progressive myelopathy. However, despite high-resolution of this exam, care must be taken not to fall into the image's pitfall of these entities. Spinal cord infarction related to spinal AVFs may mimic an intramedullary tumor, leading even expert physicians to make mistake of diagnosis. Moreover, other vascular malformations may be associated to AVFs in the nervous system. We report a rare case of spinal intradural AVFs mimicking an intramedullary tumor, which were surprisingly associated with a giant intracranial aneurysm.

1. Neurosurgeon, NEURON Institute of Neurosurgery, Baía Sul Hospital, Florianópolis, SC, Brazil, associate professor, Division of Neurosurgery, Federal University of Santa Catarina, Florianópolis, SC, Brazil.

2. Assistant neurosurgeon, Department of Neurosurgery, Bonsucesso Federal Hospital, Rio de Janeiro, RJ, Brazil.

3. Head, Department of Neurosurgery, Bonsucesso Federal Hospital, Rio de Janeiro, RJ, Brazil. 


\section{Case report}

\section{History}

A 62-year-old Caucasian woman was referred to our hospital complaining of low-back pain for 4 years associated to a progressive lower-extremity weakness and intermittent urinary incontinence over the past 2 years. At the time of presentation the patient has exhibited paraplegia for 2 months. There was no history of trauma or orthopedic deformities.

\section{Examination}

In additional paraplegia on neurological examination, we also found a bilateral anesthesia with sensitivity level at D11 dermatome, proprioceptive sensory deficit of the lower limbs, bilaterally Babinski`s sign, bladder dysfunction, and tendon reflexes were increased in the lower extremities. Unexpectedly, an unclear Hoffmann's sign in right upper extremity was found. Spine MRI findings have demonstrated an intramedullary lesion at D11-L1 levels Figures $1 \mathrm{~A}$ and B, but no changes in cervical spine. An intramedullary tumor (astrocytoma or ependymoma) had been suggested by neuroradiologists. Neurosurgical team agreed to this reasonable hypothesis and then surgical procedure was proposed to the patient. As cervical spine was no changes and Hoffmann's sign was uncertain, we did not consider this sign like an objective physical finding.

\section{Operation}

It was performed a posterior operative approach with a D10-L1 laminectomy. As soon as we had opened the dura-matter, it was unexpectedly found a numerous serpiginous vessels with medium caliber that covered posterior and lateral surface of cord extending at the conus medullaris without radicular prolongations. These lesions compressed slightly the medulla, which presented pallidal and tumescent aspect (Figure 2). We did not observe nidus. On immediately transoperative reanalysis of the spine MRI, we found multiple signal voids dots in subarachnoid space (Figure $1 \mathrm{C}$ ). Subsequently, microsurgical ligature of fistula with a dorsal venous plexus resection was successful performed.

\section{Postoperative course}

Initially, the patient reported a discreet improvement of the strength in the left leg, but not functional (muscle strength grade I). Because of the initial unvalued Hoffmann's signs and the transoperative findings, the remaining neuroaxis was investigated through angiography and magnetic resonance. Cerebral digital angiography showed a giant aneurysm in the left middle cerebral artery (MCA) that was opted for conservative treatment according to the patient's desire (Figure $1 \mathrm{D}$ ). During the follow-up period (40 months) the patient has reported lower limbs improvement with muscle strength recovered to grade III. The intracranial giant aneurysm has continued no change on angiography, and the patient has not presented new neurological findings.

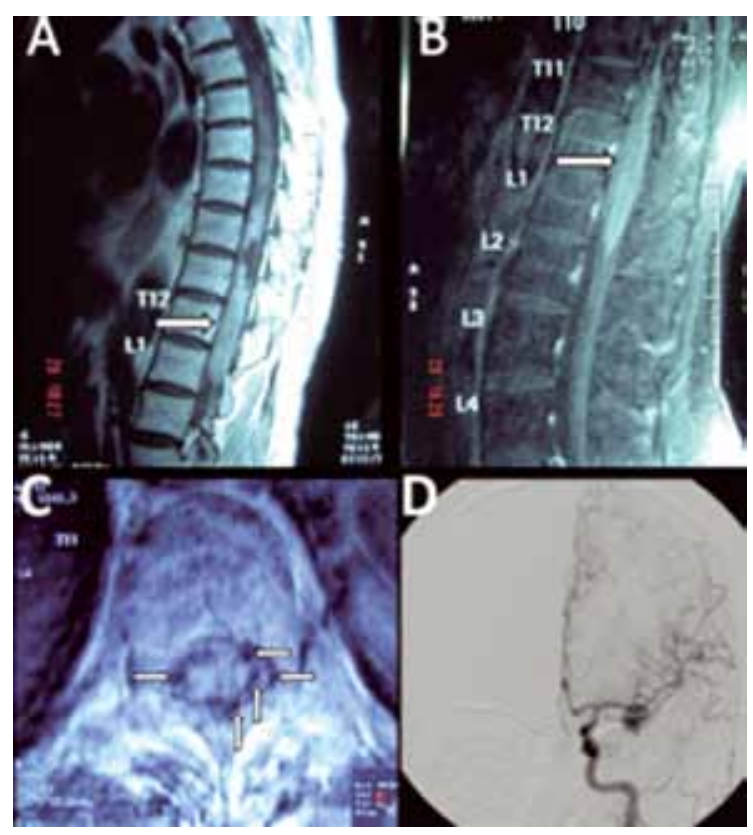

Figure 1 - Image's Studies: Thoracolumbar spine MRI $(A, B, C)$ of spinal intradural AVFs showing an intramedullary edema (white arrow) mimicking a tumor at D11-L1 levels. (A) Sagittal T1-weighted image and (B) Sagittal FLAIR sequence show a lesion with signal hyperintensity without spinal cord contrast enhancement, making it difficult to differentiate from other entities such as intramedullary tumors. (C) Axial T2-weighted MRI shows multiple intradural vessels with flow voids in dorsal and lateral subarachnoid space (white arrows). (D) Cerebral digital angiography showing a giant aneurysm in the left MCA.

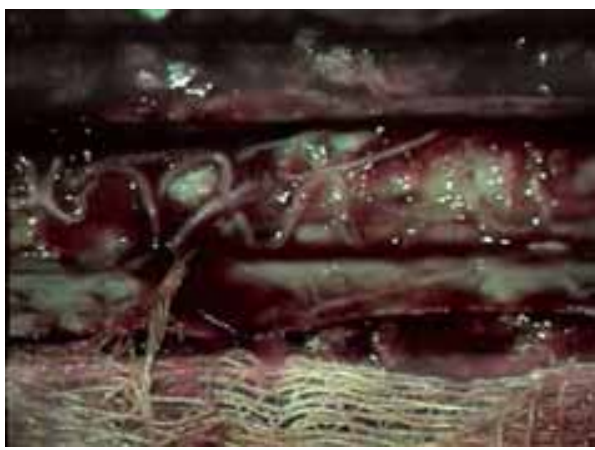

Figure 2 - Intraoperative photograph: It observes tortuous and dilated vessels with serpiginous aspect on the posterior surface of the cord. In addition to venous outflow obstruction (not shown), arterialization of these veins produces venous hypertension. Nidus was not observed. 


\section{Discussion}

According to Spetzler classification, spinal cord arteriovenous lesions are divided into arteriovenous fistulas (AVFs) and arteriovenous malformations (AVMs). Arteriovenous fistulas are subdivided into those that are extradural and those that are intradural, with intradural lesions categorized as either dorsal or ventral. ${ }^{4,8}$ Spinal intradural AVFs are uncommon lesions characterized by a direct arteriovenous shunt between a radiculomedullary artery or radiculopial and perimedullary veins located on the pial surface of the spinal cord and are usually considered to be congenital in origin. ${ }^{8}$ However, case report of the acquired spinal intradural AVFs has been published. ${ }^{3}$

The anatomical distribution of the fistula along the long axis of the spine is bimodal, predominantly in the thoracolumbar region (particularly at the conus medullaris) as seen in present case and, to a lesser extent, in the upper cervical region. Males and females are equally affected. ${ }^{4,8}$

Clinically, the patients usually present with progressive myelopathy due to venous hypertension-induced. ${ }^{4}$ Venous hypertension leads to swelling and edema into the spinal cord, the so-called state of venous congestion. It occurs in conjunction with the characteristic symptoms of a slowly progressive neurological deterioration. Most patients, regardless of which type of lesion they harbor, present with myelopathy $(80 \%)$ but no hemorrhage. Paraplegia is gradually progresses within 5 years of symptom onset. More rarely, patients have urinary, bowel, or sexual dysfunction. ${ }^{5}$
MRI is considered the first-line diagnostic modality of choice in progressive myelopathy. Findings on MRI study, such as signal abnormalities and cord enlargement are often non-specific and may result from a variety of pathologic processes in the spinal cord, including tumor, infection, and vascular diseases. Therefore, edema due to intramedullary venous congestion represents really a pitfall because can be misdiagnosed as an intramedullary tumor Figures $1 \mathrm{~A}$ and B. ${ }^{9}$ However, an apparently normal MRI study does not exclude a vascular lesion as the cause of clinical signs of myelopathy. Consequently, it is very important to know the patterns of spinal cord lesions on MRI for the differential diagnosis ${ }^{2}$ (Table 1).

The characteristic MRI findings of spinal intradural AVFs are extramedullary intradural alterations such as dilated vessels with multiple signal voids (Figure $1 \mathrm{C}$ ) or subarachnoid hemorrhages. ${ }^{5}$ When a spinal vascular malformation is suspected based on MRI and neurological symptoms, selective spinal angiography should be conducted in order to determine the type (AVM or AVF) and flow (high or low) of the vascular malformation, besides helping to determine the appropriate treatment. ${ }^{10}$

Spinal intradural AVFs can be treated with surgery, embolization, or both. Authors agree that surgery is optimum for two reasons. First, the embolization is associated with a high risk of occlusion of the anterior spinal artery or its branches ${ }^{7}$ and the rates of recurrence and progressive myelopathy associated with embolization are high. Second, according to surgical series, the reported morbidity rate is extremely low and the success rate high. ${ }^{6}$

\begin{tabular}{|c|c|c|c|}
\hline & Signal & Contrast enhancement & Hypotesis \\
\hline Pattern 1 & Abnormal signal intensity on T2-weighted images & Focal solid enhancement & $\begin{array}{c}\text { Tumor (ependymoma, hemangioblastoma, } \\
\text { metastasis, astrocytoma, lymphoma) } \\
\text { Myelitis } \\
\text { Infarction }\end{array}$ \\
\hline Pattern 2 & Abnormal signal intensity on $\mathrm{T} 2$-weighted images & Nonsolid enhancement & $\begin{array}{c}\text { Tumor (astrocytoma, ependymoma, lymphoma) } \\
\text { Infarction, spinal AVF* } \\
\text { Myelitis }\end{array}$ \\
\hline Pattern 3 & Hyperintensity on T2-weighted images & No & $\begin{array}{c}\text { Myelitis } \\
\text { Infarction, spinal AVF* } \\
\text { Tumor (astrocytoma) } \\
\text { Others }\end{array}$ \\
\hline Pattern 4 & $\begin{array}{l}\text { Mixed hypointense and hyperintense signal } \\
\text { abnormalities on T1-weighted and T2-weighted images }\end{array}$ & - & $\begin{array}{l}\text { Hemorrhagic tumors (astrocytoma, } \\
\text { ependymoma, metastasis) } \\
\text { Cavernous hemangioma, spinal AVF* } \\
\text { Posttraumatic hemorrhagic contusion }\end{array}$ \\
\hline Pattern 5 & Hyperintense and inhomogeneous lesion & Leptomeningeal enhancement & $\begin{array}{c}\text { Tumor (Metastasis, lymphoma, leukemia) } \\
\text { Myelitis }\end{array}$ \\
\hline Pattern 6 & $\begin{array}{l}\text { Diffuse atrophy of the spinal cord with or } \\
\text { without abnormal signal intensity }\end{array}$ & No & $\begin{array}{l}\text { Hereditary (adrenoleukodystrophy, hereditary } \\
\text { ataxia with cord degeneration) } \\
\text { Others (multiple sclerosis, AIDS vacuolar } \\
\text { myelopathy and tract pallor, amyotrophic } \\
\text { lateral sclerosis, posttraumatic atrophy) }\end{array}$ \\
\hline
\end{tabular}

*AVF: arteriovenous fistula. 
The common association between arteriovenous malformations in tandem with aneurysms (and vice versa) in the nervous system is well known and suggests that hemodynamic stress is the significant factor in the development of both lesions when found simultaneously. However in our case we found two neurovascular lesions in uncorrelated site. Thus, although increased blood flow seems to be an important factor in formation of these aneurysms associated with AVMs, the role of a developmental vascular anomaly also must be hypothesized. ${ }^{1}$ To the authors' knowledge, the association of these two concurrent vascular lesions has not been previously reported.

\section{Conclusion}

In conclusion, MRI findings of spinal intradural AVF may be misdiagnosed as intramedullary tumor because of edema associated to intramedullary venous congestion. Cases as seen in present study require careful differential diagnosis from intramedullary lesions. The present study also emphasizes the role of neurological exam, and that even an unclear sign can represent an important pathology requiring further investigation. Spinal intradural AVFs in association with giant intracranial aneurysm have not been previously reported. Whether this concurrence is purely a coincidence or whether there is a pathogenetic link between them cannot be answered.

\section{References}

1. Biondi A, Merland JJ, Hodes JE, Pruvo JP, Reizine D. Aneurysms of spinal arteries associated with intramedullary arteriovenous malformations. I. Angiographic and clinical aspects. AJNR Am J Neuroradiol. 1992;13(3):913-22.

2. Bourgouin PM, Lesage J, Fontaine S, Konan A, Roy D, Bard $C$, et al. A pattern approach to the differential diagnosis of intramedullary spinal cord lesions on MR imaging. AJR Am J Roentgenol. 1998;170(6):1645-9.

3. Cho JH, Ahn JY, Kuh SU, Chin DK, Yoon YS. Acquired spinal extradural arteriovenous fistula after instrumented lumbar surgery. Case illustration. J Neurosurg Spine. 2008;9(1):83.

4. Kim LJ, Spetzler RF. Classification and surgical management of spinal arteriovenous lesions: arteriovenous fistulae and arteriovenous malformations. Neurosurgery. 2006;59(5 Suppl 3):S195-201.

5. Koenig E, Thron A, Schrader V, Dichgans J. Spinal arteriovenous malformations and fistulae: clinical, neuroradiological and neurophysiological findings. J Neurol. 1989;236(5):260-6.

6. Lee TT, Gromelski EB, Bowen BC, Green BA. Diagnostic and surgical management of spinal dural arteriovenous fistulas. Neurosurgery. 1998;43(2):242-6.

7. Meisel HJ, Lasjaunias P, Brock M. Modern management of spinal and spinal cord vascular lesions. Minim Invasive Neurosurg. 1995;38(4):138-45.

8. Mourier KL, Gobin YP, George B, Lot G, Merland JJ. Intradural perimedullary arteriovenous fistulae: results of surgical and endovascular treatment in a series of 35 cases. Neurosurgery. 1993;32(6):885-91.

9. Roccatagliata L, Centanaro F, Castellan L. Venous congestive myelopathy in spinal dural arteriovenous fistula mimicking neoplasia. Neurol Sci. 2007;28(4):212-5

10. Touho H, Karasawa J, Ohnishi H, Yamada K, Shibamoto K. Superselective embolization of spinal arteriovenous malformations using the Tracker catheter. Surg Neurol. 1992;38(2):85-94.

Correspondence address

Wuilker Knoner Campos

Instituto de Neurocirurgia NEURON, sala 419 - Baía Sul Medical Center

Rua Menino Deus, 63

88020-210 - Florianópolis, SC, Brazil

Telefax: (+55 48) 3224-0843

E-mail: wuilker@yahoo.com.br 